\title{
A glut of gibbons in Sarawak - is rehabilitation the answer?
}

\author{
Jane Bennett
}

Bornean gibbons Hylobates muelleri are protected by law in Sarawak, but their habitat is being destroyed, they are illegally hunted, and they are captured for the pet trade. The Wildlife Rehabilitation Centre at Semengok Forest Reserve, which is run by the National Parks and Wildlife Office of the Sarawak Forest Department, receives confiscated gibbons and those surrendered by the general public. Between October 1976 and June 1988, 122 gibbons were received and 87 were subsequently released. The rate of survival was unknown until the author organized a survey of the forest at Semengok in 1988. It revealed that about 90 per cent of the gibbons did not survive long after release. The author discusses the reasons for this high mortality rate, the shortcomings of rehabilitation as a conservation tool, the problems facing the conservation authorities, and options for dealing with confiscated primates.

If the gibbons are silent...this is a very bad sign, and augers the approach of a serious sickness or epidemic. (Harrisson, 1966)

\section{Introduction}

The Bornean gibbon Hylobates muelleri is a diurnal, arboreal ape found in mixed dipterocarp forests throughout Sarawak (Payne et al., 1985). Like other species of gibbon it feeds on ripe fleshy fruits, young leaves and small insects (Gittins and Raemaekers, 1980; Payne et al., 1985) and lives in strongly bonded monogamous pairs (Preuschoft et al., 1984). Gibbons are territorial and duets sung by pairs at dawn serve to define the territories and strengthen the pair bond. Offspring remain with the parents until the age of $7-8$ years, forming family groups of up to six members (Gittins and Raemaekers, 1980). Both males and females show aggression towards other gibbons of the same sex entering their territory (Chivers, 1980; Preuschoft et al., 1984). Females tend to be codominant, but occasionally dominant, over male gibbons and female aggression may increase in unstable social circumstances, such as with a newly paired or widowed female (Chivers and Raemaekers, 1980; Leighton, 1986).

Estimates of home ranges for gibbons in the wild (all species) average 34 ha, with a range of 16-54 ha (Gittins, 1984; Srikosamatara, 1984; Leighton, 1986). Territories (or defended portions) average 75 per cent of the home range (Leighton, 1986). Variations in home ranges may be influenced by the overall availability of food (Ellefson, 1974), variations in food tree species (Marsh and Wilson, 1981) and water sources (Berkson et al., 1971). Some groups have been found persisting in isolated forest patches as small as 4.5-5.7 ha (Berkson et al., 1971), although it is unlikely that such populations are viable in the long term.

The bubbling cry of the female gibbon can carry over a distance of a kilometre and it is one of the most thrilling and melodic sounds of the forest. Unfortunately, this call makes gibbons easy prey for hunters. Hunting has increasea with easier access to the forest due to logging. In areas where preferred game species, such as pig and deer, are declining primates are often hunted for food (Caldecott, 1988). Baby gibbons are frequently kept as pets and are usually obtained by killing the parents (Kavanagh, 1986). 
Bornean gibbons are classified as vulnerable by the IUCN (1986) and are a totally protected species under the Wild Life Protection Ordinance in Sarawak. Keeping gibbons as pets is illegal and the National Parks and Wildlife Office (NPWO) of the Sarawak Forest Department is empowered to confiscate or, in special circumstances to issue licences for, captive gibbons. Confiscated animals are sent to the Wildlife Rehabilitation Centre (WRC) at Semengok Forest Reserve $19 \mathrm{~km}$ south of Kuching. Semengok is an area of primary and secondary mixed dipterocarp forest with some kerangas forest (tropical heath forest; the native term denotes land too poor to grow rice). The terrain is undulating and there are several permanent streams. Its total area of 650 ha includes an arboretum, a Forest Department nursery and botanical research centre (Lee, 1984). The remaining forest has been disturbed in parts for experimental plantation plots and is surrounded by agricultural land and villages. Although the forest may have contained gibbons in the past, they were not present at the time the WRC was established.

The aim of the WRC is to rehabilitate confiscated animals and return them to the wild. Bornean gibbons have been the most common species of animal confiscated, with a total of 122 arriving at Semengok between October 1976 and June 1988. Only casual observations were made of released animals, until 1988 when the present study carried out surveys to assess the success of the gibbon rehabilitation work.

\section{Methods}

\section{Rehabilitation and release}

Gibbons arrived at Semengok after veterinary checks and were placed in holding cages in a forest clearing. The WRC records show that gibbons were released into the forest at varying times after their arrival, depending on the availability of cage space. Where possible males and females were paired in cages prior to release to try and establish a pair bond but not all the gibbons in this study were given adequate opportunities to learn behaviour to prepare them for life in the wild.

\section{Surveys}

For the specific purposes of the surveys Forest Department staff cut a total of $9.5 \mathrm{~km}$ of trails in the forest adjacent to the WRC some months before the surveys started. These were in the form of grid squares with sides $500 \mathrm{~m}$ long. Surveys were conducted along these trails as well as along the board-walk access to the WRC and along the arboretum border (Figure 1).

Surveys by the author and the NPWO field staff, who were experienced in forest wildlife survey techniques, took place on eight mornings between 4 February and 31 March 1988. On any one morning three or four people

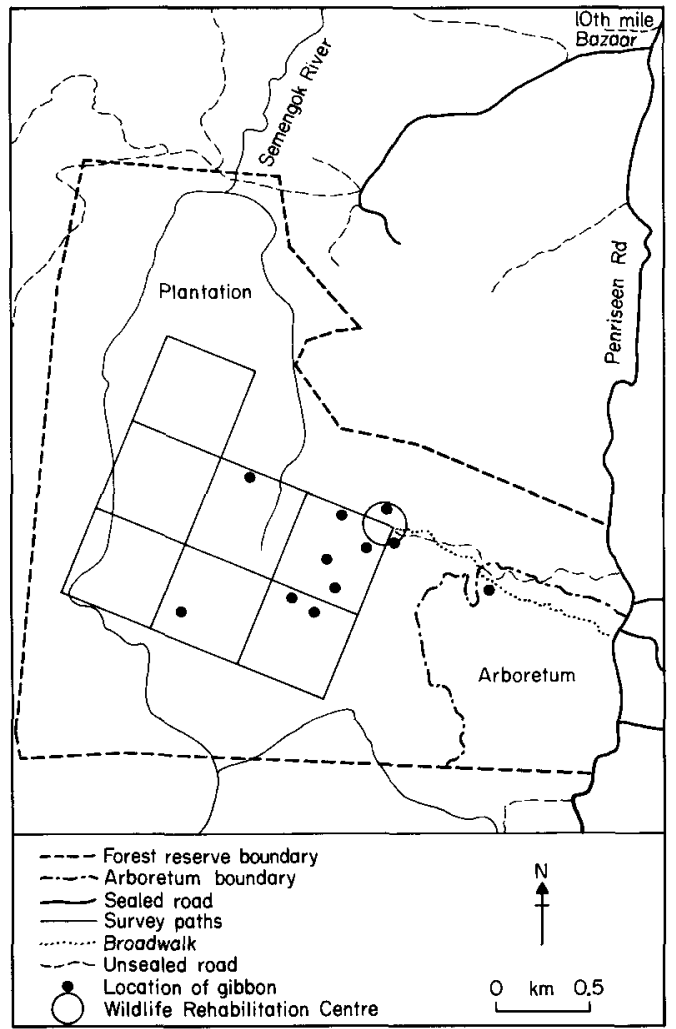

Figure 1. Semengok Wildlife Rehabilitation Centre, showing the various land uses, survey paths, and locations of gibbons (individuals and groups) detected during surveys. 
walked separate transects. Because gibbons tend not to call in the rain, surveys were conducted only on fine mornings (Chivers and Raemaekers, 1980; Gittins and Tilson, 1984; Kappeler, 1984). Observers departed from the WRC between 05.30 and $06.00 \mathrm{~h}$ and dispersed along the transect grid or board-walk. Each observer covered between 2-4 km, walking slowly and returning to the WRC between 08.45 and $10.00 \mathrm{~h}$. When gibbon calls were heard compass bearings were taken from two positions at least $100 \mathrm{~m}$ apart in order to plot the position by triangulation. Sightings of calling gibbons were recorded to assess numbers and identify individuals. Observers also looked for silent gibbons.

Calls could be heard over distances of at least $1 \mathrm{~km}$ in the undulating terrain of the transect area. Although the transect grid does not cover the entire reserve, including the board-walk and part of the arboretum border meant that available gibbon habitat was well covered.

\section{Results}

\section{Rehabilitation and release}

The volume of animals passing through the programme, combined with low supervision and staffing levels, meant that gibbons were occasionally released as young as 4 months of age, and some within days of being received. Records kept by the WRC show that more male gibbons than female were received; the reasons for this are not clear. Although there were records on arrivals and mortalities, there was none on progress during rehabilitation or follow-up of individual gibbons after release (Table 1).

\section{Survey results}

Calls were heard on six of the eight survey mornings, all between 06.00 and $08.30 \mathrm{~h}$. Calls at other times of the day were heard from Ali, a tame but free female, who often called within hearing range of the WRC buildings. The maximum number of calling groups in any one morning was three and the existence of at least three separate groups was confirmed by observation. One group consisted of four individuals of undetermined sex and age, another of two individuals, one of whom was female, and a lone individual female (Ali). No silent gibbons were seen. Other calls may be attributable to as yet unidentified individuals, but it appears that the number of gibbons remaining in the forest at Semengok is unlikely to exceed 10 .

The locations of calling groups are shown in Figure 1. The area where most of the calls were heard is the least disturbed part of the forest and contains permanent streams. Only one call was heard from the arboretum close to the WRC, and this was probably Ali who has been observed in the area (pers. obs.). Interviews with local residents and WRC workers revealed that gibbon calls used to be heard regularly from the arboretum, but these ceased sometime during the year preceding the survey.

\section{Mortality}

Of the 87 gibbons released at Semengok (Table 1) it appeared that fewer than 10 survived at the time of the survey. This represents a mortality rate of 90 per cent. Nine gibbons died in captivity at the WRC within 2 months of arrival, probably due to ill health at confiscation. There are records showing that 30 gibbons died in all, some after release. Thus, whereas only 25 per cent mortality has been recorded in the WRC records for the 122 gibbons received at Semengok, the results of this survey, when combined with existing records, indicate a total overall mortality rate for confiscated (as opposed to released) gibbons of 95 per cent.

\section{Discussion}

\section{Gibbon rehabilitation}

The most detailed information available on gibbon rehabilitation has emerged from the free-ranging colony of lar gibbons Hylobates lar 
established on Ko Klet Kaeo, a 24.3-ha island in the Gulf of Thailand. Of 21 gibbons introduced there, four pairs established territories. The rest either died or were returned to the caged laboratory colony because they did not adjust, or interfered with other pairs, an attrition rate of 62 per cent. Four young were born and successfully reared during the 4-year study (Berkson et al., 1971; Brockelman et al., 1973; Brockelman et al., 1974).

Klo Klet Kaeo is not natural gibbon habitat. It is covered by trees $5-15 \mathrm{~m}$ tall and released gibbons were provided with artificial sources of food and water throughout the island to supplement natural food sources. Preliminary caging in pairs increased the likelihood of stable pair bonds forming. Young animals that had already established social relationships with humans tended not to pair as successfully as gibbons reared in the wild. Aggressive behaviour towards other gibbons and humans was common, as was a tendency by some animals to walk along paths rather than remaining arboreal. Home ranges did not cover the full extent of the island (Berkson et al,, 1971; Brockelman et al., 1973).

There are many differences between the release sites in Thailand and Sarawak. The forest at Semengok is similar to the habitat of existing populations of gibbons, unlike Ko Klet Kaeo. It is not known whether gibbons occurred at Semengok in the past, but it is highly probable that they did. Semengok is much larger than Ko Klet Kaeo and is bordered by villages and cultivation. Numerous paths are used as thoroughfares by local residents for reaching the bazaar as well as for illegal hunting.

Released animals at Semengok were not provided with supplementary food and water, nor was there sufficient follow-up to assess the programme. At Ko Klet Kaeo small numbers were released and kept under constant observation, enabling a far more detailed assessment.

Rehabilitation at Semengok appears to have been less successful than at Ko Klet Kaeo, with mortality exceeding 90 per cent. As on Ko Klet Kaeo, one of the groups almost certainly contains more than two adults (sex unknown) and home ranges have not expanded to fill the available space. There are definitely three, and possibly four, groups remaining in the reserve at Semengok. According to anecdotal reports from staff at WRC, some rehabilitants have successfully reared offspring. Unfortunately, there are no records to support these observations and it was not possible to identify individuals positively in order to correlate with available records.

\section{Factors contributing to mortality at Semengok}

The main factors likely to be causing mortality at Semengok can be summarized as starvation, disease, hunting and aggressive territorial disputes.

The survival of released animals must depend to a large extent on the length and quality of the rehabilitation phase. Immediate release does not allow for a quarantine period to assess nutritional, health and behavioural status. Some of the gibbons were released at an age when they would still be suckling in the wild. Others, which had been in captivity since infancy and had been fed on rice and bananas, would not have developed the foraging skills required to avert starvation. Releasing so many gibbons at a single site means that territorial disputes are likely to occur. Aggressive encounters have been observed between gibbons at the Rehabilitation Centre at Semengok; some were severe enough to be fatal. Territorial disputes, combined with poor foraging skills and the presence of any diseases, reduce the potential

Table 1. Fate of 122 gibbons arriving at Semengok Wildlife Rehabilitation Centre, October 1976-June 1988. Numbers in parentheses indicate the number that died within 8 weeks of arrival

\begin{tabular}{lrrr}
\hline & Male & Female & Total \\
\hline Still in captivity & 2 & 2 & 4 \\
Known to have died & 20 & 10 & 30 \\
& $(5)$ & $(4)$ & $(9)$ \\
Released, fate unknown & 66 & 21 & 87 \\
Released, still seen & 0 & 1 & 1 \\
Total & 88 & 34 & 122 \\
\hline
\end{tabular}


for survival. In addition to these influences, hunting also occurs in the reserve, which is close to the city and villages, has an incomplete boundary fence and is not patrolled.

\section{Distribution}

Wild gibbons have home ranges of approximately 34 ha so, assuming a 20 per cent overlap in ranges, the four groups at Semengok would be expected to need about 110 ha. Although not all the 650 ha of the reserve is available, some being used for plantations, nurseries or buildings, this suggests that less than half the available area is being used. There are a number of possible reasons for this: a large part of the reserve might be unsuitable habitat; the habitat might be so marginal that enlarged home ranges are required; the released gibbons have abnormal social behaviour, restricting density; and other factors contributing to mortality (see above). It was not possible to estimate actual home ranges of established rehabilitant groups with the available data.

Although there would appear to be space available for more gibbons in the reserve, the small number of gibbons that have established territories suggest that extrapolating from data on wild gibbon home ranges may be inappropriate. Gibbons released from rehabilitation programmes have usually been handreared from a young age and therefore are likely to exhibit abnormal behaviour. This is an important consideration for future release programmes for any animal. It is not possible to choose a piece of land, divide it up into home ranges and release a calculated number of animals into it. Factors limiting the population of reintroduced animals are not well understood. For gibbons, behavioural maladjustment and specific habitat preferences may contribute significantly to limiting population densities of released animals.

\section{Options for confiscated gibbons}

Options for confiscated primates have been fully discussed by Harcourt (1987):

* euthanasia;

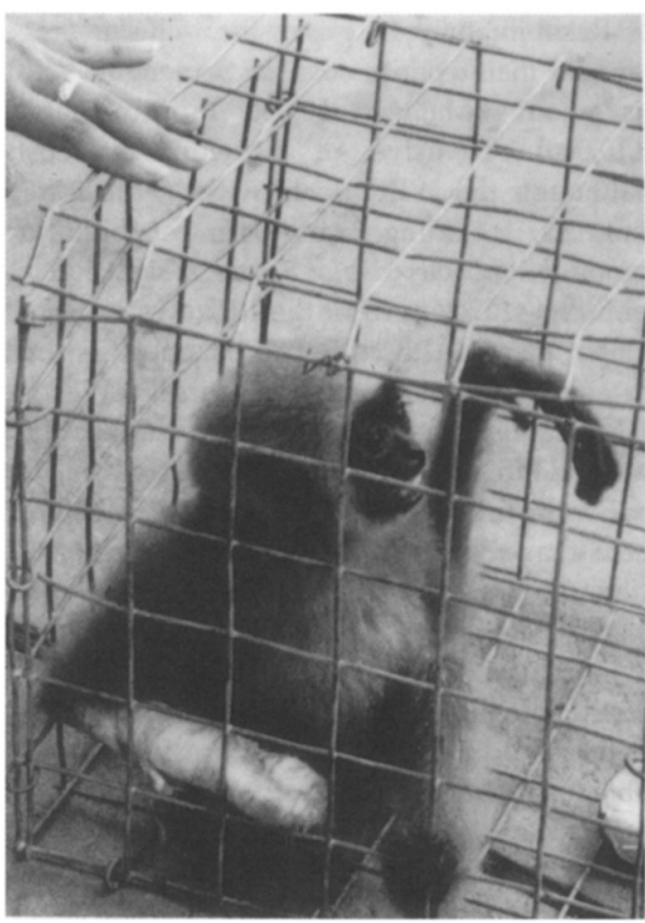

Gibbons confiscated or surrendered to Semengok Wildlife Rehabilitation Centre have often been kept in tiny cages with poor nutrition. Rehabilitation needs to address health status at arrival as well as preparing gibbons for release to the forest (Jane Bennett).

* use of the body or its parts for research or teaching purposes;

* export to captivity abroad;

* captivity in country of origin;

* release to the wild.

Rehabilitation of confiscated gibbons for release to the wild cannot be justified for either conservation education or tourism purposes, as released gibbons are potentially aggressive or usually so shy as to be invisible to visitors.

Although 122 gibbons passed through the WRC over a period of 11 years, in 1988 there were probably at least 50 gibbons being kept privately in Sarawak's major towns and an unknown number involved in the pet trade or being kept in rural areas. Thus the WRC sees only a fraction of all gibbons displaced from the forest and already has resources stretched to the limits. 
Rehabilitation is expensive. The average annual maintenance cost for Semengok WRC is about $\$$ Malaysian50,000 (approximately $£ 10,000$ ), exclusive of development costs (although the WRC deals with all protected animals, including orang-utan rehabilitation among its activities). Semengok WRC is entirely funded by the Sarawak Forest Department. Although this is cheaper than establishing breeding facilities in the West, it is arguable whether this is the most appropriate and efficient use of allocated resources.

For the gibbon, there is a greater than 90 per cent chance of death in the forest from starvation, disease, aggression or hunting if the project is inadequately planned and supervised. As many of these animals are in captivity as a result of habitat destruction and hunting, there may be insufficient secure forest available for their release.

The high levels of mortality and aggression observed in this study indicate that release is a highly stressful, if not fatal, process for gibbons. In contrast, pairs of caged gibbons can remain active and healthy and do not show the same degree of boredom and attentionseeking behaviour as do young captive orangutans (pers. obs.) Given the options currently available in Sarawak, release of gibbons is best discontinued, with confiscated gibbons kept in suitable enclosures, preferably in compatible pairs, where they can be used for conservation education or captive-breeding purposes either in Sarawak or abroad.

The fact that any gibbons survive at all after release suggests that it ought to be possible to restock areas that have been hunted out, if greater individual attention is given to rehabilitation and if suitable release sites are available. However, many captive gibbons have been reared in isolation without the skills to survive in the forest and are consequently poor candidates for rehabilitation.

Until suitable facilities are available to care for captive animals in Sarawak, then export to other countries for display and breeding purposes in reputable zoos should be considered. There are fewer than 50 Bornean gibbons in the world's zoos and the true number is probably lower due to taxonomic confusion with the Javan gibbon H. moloch (Schmidt, 1986). With such low numbers it is unlikely that a sustainable genetic pool of this species can be maintained by zoos.

Another alternative is to use the surplus animals for biomedical research. Primates have been used extensively as models for humans in medical research. It is beyond the scope of this paper to discuss the ethical dilemmas surrounding the use of primates for research and these must be weighed against those related to the final option of euthanasia.

Many gibbons kept in captivity, particularly those kept alone as pets, can be regarded as 'dead' in terms of their ability to contribute to the species gene pool, because they have no opportunity to breed. In conservation terms it makes no difference whether these animals stay in captivity or are killed. The commonly cited justifications for keeping animals in captivity are for the purposes of conservation education, research or breeding. However, in Sarawak, there are currently enough animals at Semengok for these purposes. In addition, there are inadequate facilities to accommodate the numerous gibbons being kept as pets were they all to be confiscated. Many of these are being kept in very poor conditions and although licences can be issued for keeping protected species, there are no housing requirements or inspection clauses under current legislation. In cases where animals are found to be in poor condition or where facilities are inadequate or cruel, euthanasia may be the appropriate option. As a veterinarian, I would recommend this in preference to use in biomedical research if no other option were available.

Euthanasia is a difficult and controversial option. The decision to employ it should be based on whether it is more humane to end a life rather than allow it to continue in its present state. It can be argued that for gibbons and many other animals, solitary confinement (often in a small cage), an artificial diet, restricted movement (there are often no furnishings and usually inadequate space to allow brachiation), and no opportunity to breed, is a stressful and inhumane existence. For released animals, death by slow starvation 
or from harassment in an overcrowded reserve may also be considered cruel and inhumane. Rather than allowing wildlife legislation to appear impotent, euthanasia may allow a greater degree of enforcement and also save individual gibbons from prolonged stress once displaced from their native forest.

This dilemma is not restricted to Sarawak, or to this species. There are gluts of captive and confiscated gibbons in Sabah and peninsular Malaysia (pers. obs.) and Thailand (W. Brockelman, pers. comm.). All these areas also have forest areas where gibbon populations have been hunted to extinction locally. Wildlife authorities cannot cope with the numbers of gibbons in captivity and gibbons are often (sometimes secretly) released in order to free cage space. Although humans derive personal gratification from releasing other animals to their natural environment, this may be a misguided benevolence. As painful and difficult as the decision to kill an animal may be, if the welfare of the animal involved is truly being considered over and above the sensibilities of the decision-maker, this option should be considered among all others before releasing such animals to an uncertain fate.

The question of euthanasia is one that may seem to conflict with the concept of wildlife conservation. However, I would argue that in terms of species conservation, the prime objective should be to conserve that species in the context of its environment. Keeping alive individual animals outside that context, or individuals who cannot survive in that context, is of lesser significance to the conservation of that species as a whole and is usually assessed in terms of potential of those animals to contribute to the captive gene pool. The allocation of resources to the maintenance and rehabilitation of displaced animals must be assessed within the framework of potential contribution to the (existing or imagined) conservation strategy for that species. The meagre allocation of resources and rearguard nature of most wildlife conservation activities calls for economy of effort for maximum effect. This study illustrates the low return on one such project and calls for greater attention to determining priorities and exploring possible options in these situations.

\section{Conclusions}

The principal threats to gibbon populations in Sarawak are hunting and habitat destruction (Bennett et al., 1985; Kavanagh, 1986). The results of the gibbon rehabilitation project at Semengok to date show that releasing confiscated gibbons to the forest can be highly ineffective, potentially inhumane, and has not contributed significantly to their conservation. Rehabilitation and release have succeeded in returning some animals to the wild, but the costs have been great. Individual animals need to be assessed and a range of options considered in concert with rehabilitation, from captive-breeding through to euthanasia.

The future of gibbon populations cannot depend on rehabilitation and release alone. Rather a multifaceted approach is necessary, with an emphasis on education, along with greater government efforts to reduce hunting, promote conservation and protect adequate areas of tropical rain-forest habitat.

\section{Acknowledgments}

This paper arose from my work with the Sarawak Forest Department as a volunteer with Australian Volunteers Abroad from 1987 to 1989 . I thank the Sarawak State Government for making this possible. Credit is due to all staff of National Parks and Wildlife Office involved with this project over the years for making the best of a difficult task. This includes David Labang, Ken Proud, Bangan ak Empulu, the late Moray Lewis and Thulu Ayu. Thanks to all field staff who assisted in my surveys, notably Abang Mutalib. This paper would not have been possible without the support of Philip Ngau Jalong and Francis Gombek of NPWO and the editing and encouragement of Drs Elizabeth L. Bennett, Julian O. Caldecott and Warren Y. Brockelman, as well as David Slip's red pen.

\section{References}

Bennett, E.L., Caldecott, J.O., Kavanagh, M. and Sebastian, A.C. 1985. Conservation status of Sarawak's primates. Sarawak Gazette, 111, 30-34. 
Berkson, G., Ross, B.A. and Jatinandana, S. 1971. The social behaviour of gibbons in relation to a conservation program. In Primate Behaviour: Developments in Field and Laboratory Research (ed. L. A. Rosenblum), Vol. 2 pp. 225-255. Academic Press, New York.

Brockelman, W.Y., Ross, B.A. and Pantuwatana, S. 1973. Social correlates of reproductive success in the gibbon colony on Ko Klet Kaeo, Thailand. Am. J. Phys. Anthrop., 38, 637-640.

Brockelman, W.Y., Ross, B.A. and Pantuwatana, S. 1974. Social interactions of adult gibbons (Hylobates lar) in an experimental colony. In Gibbon and Siamang (ed. D. M. Rumbaugh), Vol. 3. Karger, Basel.

Caldecott, J.O. 1988. Hunting and Wildlife Management in Sarawak. The IUCN Tropical Forest Programme, International Union for Conservation of Nature and Natural Resources, Switzerland.

Chivers, D.J. 1980. (ed.) Malayan Forest Primates: Ten Years Study in Tropical Rain Forest. Plenum Press, New York and London.

Chivers, D.J. and Raemaekers, J.J. 1980. Long term changes in behaviour. In Malayan Forest Primates: Ten Years Study in Tropical Rain Forest (ed. D. J. Chivers). Plenum Press, New York and London.

Ellefson, J.O. 1974. A natural history of white-handed gibbons in the Malayan peninsula. In Gibbon and Siamang (ed. D. M. Rumbaugh), Vol. 3. Karger, Basel.

Gittins, S.P. 1984. Territorial advertisement and defence in gibbons. In The Lesser Apes Evolutionary and Behavioural Biology (eds $\mathrm{H}$. Preuschoft, D. J. Chivers, W. Y. Brockelman and N. Creel). Edinburgh University Press, Edinburgh.

Gittins, S.P. and Raemaekers, J.J. 1980. Siamang, lar and agile gibbons. In Malayan Forest Primates: Ten Years Study in Tropical Rain Forest (ed. D. J. Chivers). Plenum Press, New York and London..

Gittins, S. P. and Tilson, R.L. 1984. Notes on the ecology and behaviour of the hoolock gibbon. In The Lesser Apes-Evolutionary and Behavioural Biology (eds H. Preuschoft, D. J. Chivers, W. Y. Brockelman and N. Creel). Edinburgh University Press, Edinburgh.
Harcourt, A.H. 1987. Options for unwanted or confiscated primates. Primate Conservation, 8, 111-113.

Harrisson, T. 1966. The gibbon in West Borneo folklore and augury. Sar. Mus. Journ. XIV, 428-429 (NS); $132-145$.

IUCN. 1986. 1986 Red List of Threatened Species. IUCN, Gland, Switzerland and Cambridge, UK.

Kappeler, M. 1984. Vocal bouts and territorial maintenance in the moloch gibbon. In The Lesser Apes Evolutionary and Behavioural Biology (eds. $\mathrm{H}$. Preuschoft, D. J. Chivers, W. Y. Brockelman and N. Creel). Edinburgh University Press, Edinburgh.

Kavanagh, M. 1986. The threatened mammals of Sarawak. In Reports and Recommendations to DUN Select Committee on Flora and Fauna in Sarawak. Part 1.

Lee, B. 1984. Semengok Forest Reserve. Family Tree, 2, 11-13.

Leighton, D.R. 1986. Gibbons: Territoriality and Monogamy. In Primate Societies (eds B. B. Smuts, D. L. Cheney, R. M. Seyforth, R. W. Wrangham and T. T. Struhsaker). University of Chicago Press, Chicago and London.

Marsh, C. W. and Wilson, W.L. 1981. A Survey of Primates in Peninsular Malaysian Forests. Universiti Kebangsaan Malaysia.

Payne, J., Francis, C.M. and Phillipps, K. 1985. A Field Guide to the Mammals of Borneo. The Sabah Society and World Wildlife Fund (Malaysia).

Preuschoft, H., Chivers, D.J., Brockelman, W.Y. and Creel, N. 1984. The Lesser Apes-Evolutionary and Behavioural Biology. Edinburgh University Press, Edinburgh.

Schmidt, C.R. 1986. A review of zoo breeding programmes for primates. Int. Zoo Yearbook, 24/25, 107-123.

Srikosamatara, S. 1984, Ecology of pileated gibbons in south-east Thailand. In The Lesser Apes Evolutionary and Behavioural Biology (eds $\mathrm{H}$. Preuschoft, D. J. Chivers, W. Y. Brockleman and N Creel). Edinburgh University Press, Edinburgh.

Jane Bennett, Centre for Environmental Studies, University of Tasmania, GPO Box 252C, Hobart, Tasmania 7001, Australia. 